(c) 2019 Elsevier Ltd. All rights reserved. This manuscript version is made available under the CCBY-NC-ND 4.0 license http://creativecommons.org/licenses/by-nc-nd/4.0/ 


\section{Accepted Manuscript}

Hybrid Liquid Desiccant System Design and Operation Under High Latent Load Conditions in Taiwan

Xabier PEÑA, Laura ALONSO , Andoni DIAZ DE MENDIBIL, Juan PRIETO , Khaled GOMMED

PII:

DOI: S0140-7007(18)30444-4

Reference: https://doi.org/10.1016/j.ijrefrig.2018.11.011 JIJR 4170

\section{refrigeration}

To appear in:

International Journal of Refrigeration

Received date:

30 December 2017

Revised date:

11 July 2018

Accepted date:

10 November 2018

Please cite this article as: Xabier PEÑA, Laura ALONSO, Andoni DIAZ DE MENDIBIL, Juan PRIETO, Khaled GOMMED, Hybrid Liquid Desiccant System Design and Operation Under High Latent Load Conditions in Taiwan, International Journal of Refrigeration (2018), doi: https://doi.org/10.1016/j.jirefrig.2018.11.011

This is a PDF file of an unedited manuscript that has been accepted for publication. As a service to our customers we are providing this early version of the manuscript. The manuscript will undergo copyediting, typesetting, and review of the resulting proof before it is published in its final form. Please note that during the production process errors may be discovered which could affect the content, and all legal disclaimers that apply to the journal pertain. 
- $\quad$ The system shows Energy Efficiency Ratios up to 4.6.

- An independent control of temperature and humidity is achieved.

- The higher the total loads the better the performance of the HLDS.

- $30 \%$ electrical energy savings are attained when compared to traditional systems.

- Efficient alternative for HVAC systems in high latent load applications.

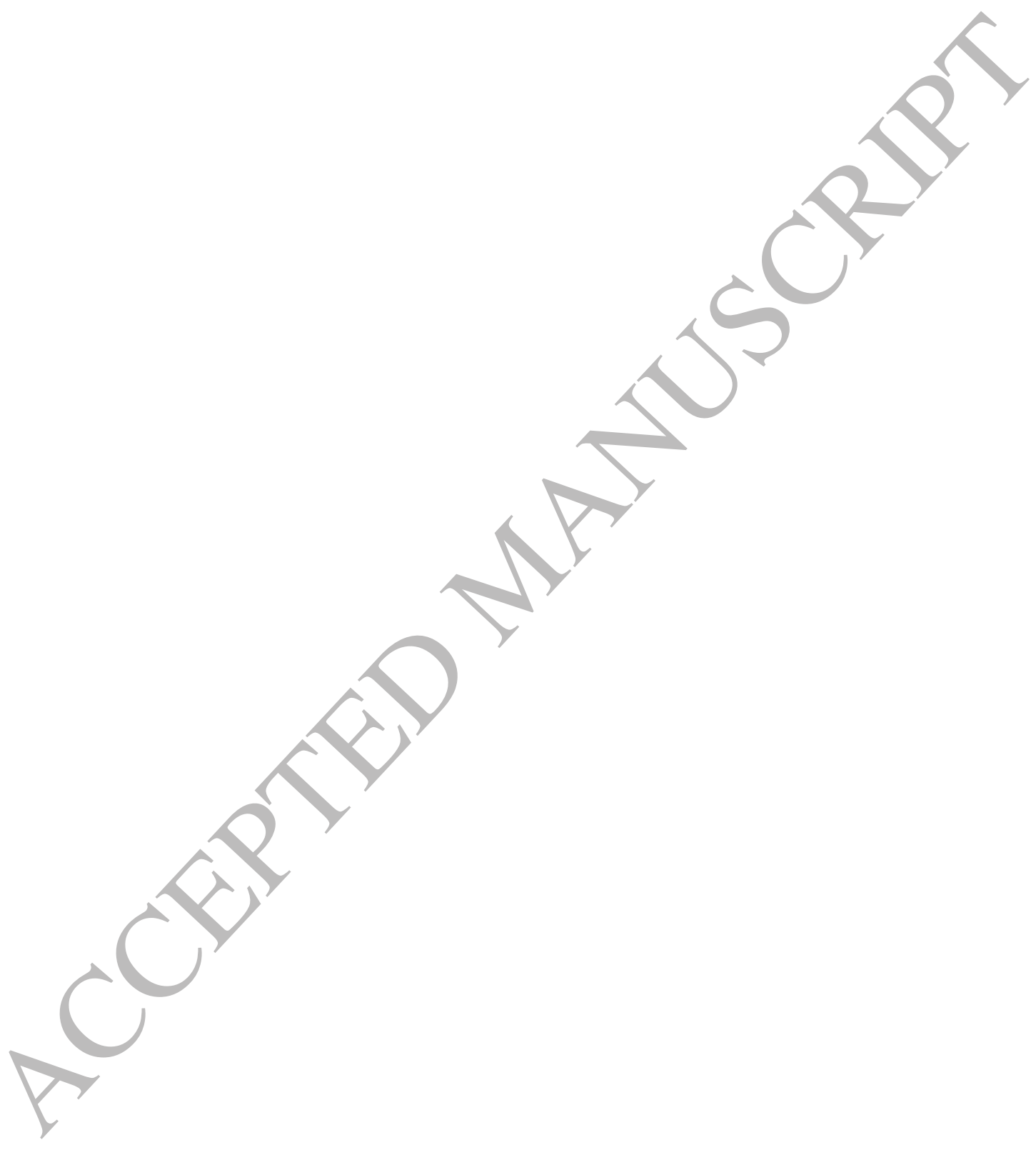




\title{
Hybrid Liquid Desiccant System Design and Operation Under High Latent Load Conditions in Taiwan
}

\section{Authors}

Xabier PEÑA ${ }^{1 *}$, Laura ALONSO ${ }^{1}$, Andoni DIAZ DE MENDIBIL ${ }^{1}$, Juan PRIETO ${ }^{2}$, Khaled GOMMED $^{3}$

*Corresponding author

${ }^{1}$ Tecnalia, Energy and Environment Division, Area Anardi, 5. Azpeitia E20730, Gipuzkoa, Spain.*xabier.pena@tecnalia.com.

${ }^{2}$ CREVER, Department of Mechanical Engineering, Universitat Rovira i Virgili, CREVER, Av. Països Catalans 26, 43007, Tarragona, Spain.

${ }^{3}$ Technion - Israel Institute of Technology, Faculty of Mechanical Engineering. Haifa 32000

Israel.

\begin{abstract}
Hybrid Liquid Desiccant systems (HLDS) combine the liquid desiccant technology for dehumidification of air with conventional compression cycle technology for cooling. They are an alternative to conventional compression cooling systems, being more efficient and offering the possibility of independently control temperature and humidity. In this paper the design and operation of a HLDS is presented, for the air conditioning of a high latent load application with high ambient humidity levels. An analysis of the daily evolution of the performance of the system under different environmental conditions has been included. The innovative demonstration unit placed in Taiwan, in continuous operation since November 2015, achieved Energy efficiency Ratios (EER) up to 4.6.
\end{abstract}

\section{Keywords}

Liquid desiccant system, HVAC, falling-film, experimental performance.

\section{Nomenclature}

Symbols

$A H U$ - Air Handling Unit

CAGR - Compound Annual Growth Rate

COP - Coefficient of performance

EER - Energy efficiency ratio

$\mathrm{H}$ - Relative humidity / \%

h $\quad$ - Enthalpy $/ \mathrm{kJ} \cdot \mathrm{kg}^{-1}$

HLDS - Hybrid Liquid Desiccant System

$H \& M T C$ - Heat \& Mass transfer coefficients

HTC $\quad$ - Heat transfer coefficient $/ \mathrm{W} \cdot \mathrm{m}^{-2} \cdot \mathrm{K}^{-1}$

$H V A C$ - Heating, Ventilation and Air Conditioning

$\mathrm{k}-$ - Factor of the fan used in the AHU

LDS - Liquid Desiccant System

LLHX - Liquid-Liquid Heat exchanger

$\mathrm{M}_{\text {sup }} \quad$ - Air mass flow rate $/ \mathrm{kg} \cdot \mathrm{s}^{-1}$

MTC - Mass transfer coefficient $/ \mathrm{kg} \cdot \mathrm{m}^{-2} \cdot \mathrm{s}^{-1}$ 


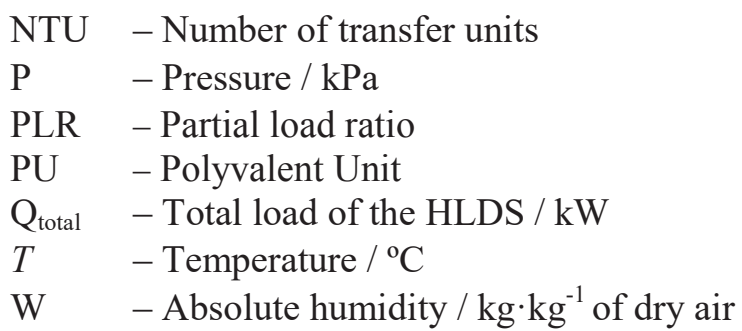

\section{Greek Symbols}

$\rho \quad-$ Density $/ \mathrm{kg} \cdot \mathrm{m}^{-3}$

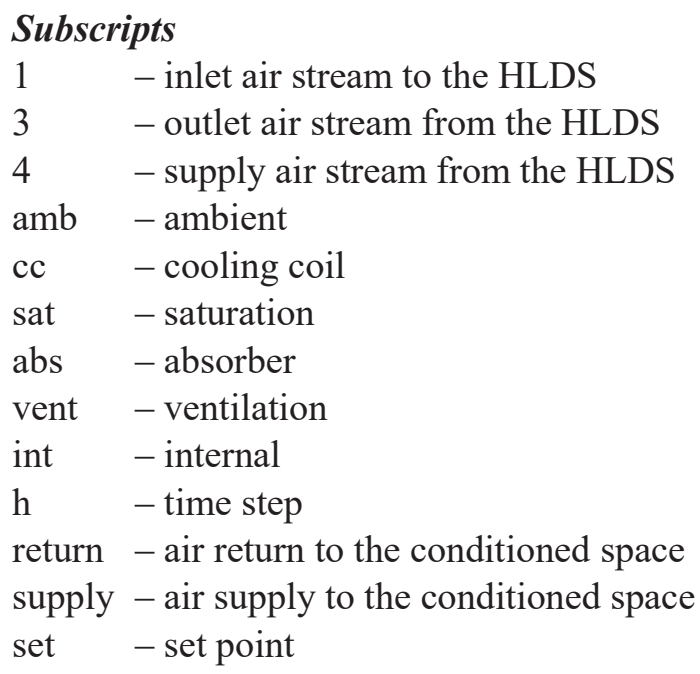

\section{Introduction}

Conventional compression air conditioning systems match the latent cooling loads by reaching the dew point of air, in order to obtain water condensation, having the need of reaching too low air temperatures. This leads to inefficient cooling and dehumidification process, for the comfort conditions achievement.

In this sense, liquid desiccant systems are appropriate for dehumidification processes [1]. In Hybrid Liquid Desiccant systems, the latent load is removed by a liquid desiccant dehumidifier, while the sensible load is removed by a conventional air conditioning system. The combination of both systems makes possible an independent control of temperature and humidity, and has been proposed as a promising alternative [2-7]. They are suitable for diverse applications, such as air conditioning in highly humid climates, like tropical or sub-tropical humid climates. Several hybrid liquid desiccant systems with vapor compression technology have been proposed in the literature for building applications [8]. Regarding the tropical and sub-tropical climates, it should be considered that Asia Pacific represented at 2016 the $53 \%$ of the HVAC market share growing at a CAGR of 3.27\% from 2016 to 2022 [9], which denotes a clear market opportunity for HLDS.

Figure 1 shows a simplified representation of the cooling and dehumidification process in a psychrometric diagram, for the conventional process (red lines) and the HLDS process (blue lines). As can be seen in the diagram, in the conventional process air needs to reach the dew point in order to condensate the water and thus eliminate the water content of air. This leads to a high reduction of the temperature of air, which needs to be reheated after cooling and dehumidification to match the comfort conditions. In the HLDS process, on the other hand, the 
air is dehumidified and cooled down at the same time, and once the required humidity level is reached, the temperature is adjusted.

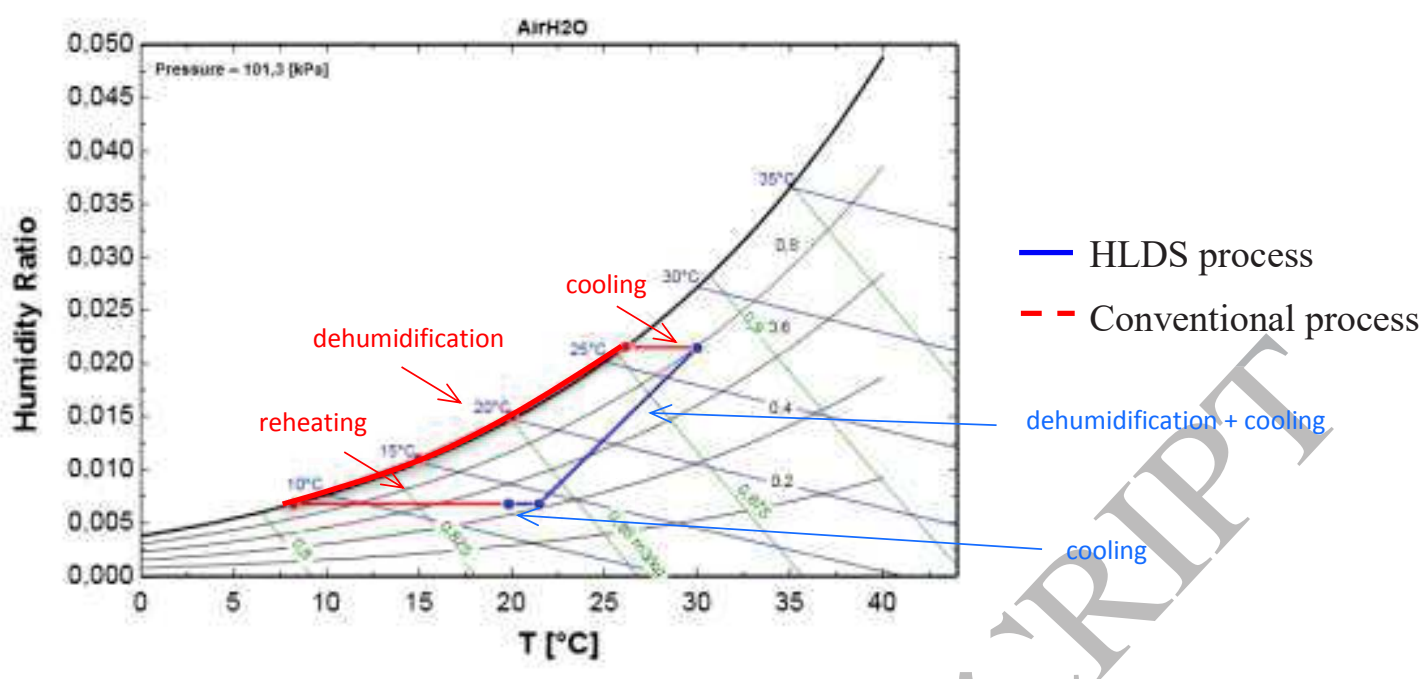

Figure 1. Comparison between a Hybrid Liquid Desiccant System and a conventional cooling and dehumidification

In this paper the design and operation of a hybrid liquid desiccant system is presented, for a case study in a swimming pool of the National Taiwan University of Science and Technology, with high internal humidity generation and also high ambient humidity levels due to subtropical humid climate present in Taiwan.

The designed HLDS has falling film type internally cooled/heated air-solution contactors (absorber and regenerator), made of polymeric tubes in order to avoid corrosion effects of the desiccant solution. The polymeric tubes have received a plasma treatment in order to increase their wettability, deeply explained in Fina et al. [10]. An improvement of the wettability and therefore the performance of the air-solution contactors has been previously experimentally evidenced [11].

\section{Design of the hybrid liquid desiccant prototype}

HLDS is comprised by the following sub-systems:

- A liquid desiccant system (LDS) whose main components are the absorber, regenerator and liquid-liquid heat exchanger. The desiccant used in this system is an aqueous solution of Lithium Chloride.

- A conventional Air Handling Unit (AHU) with a cooling coil and a cross-plate heat exchanger for ventilation heat recovery.

A polyvalent unit (PU) heat pump able to provide cooling and heating simultaneously, which feeds the absorber and the cooling coil with cold water at $15^{\circ} \mathrm{C}-17^{\circ} \mathrm{C}$, and the regenerator with hot water at $51^{\circ} \mathrm{C}-55^{\circ} \mathrm{C}$.

The diagram in Figure 2 represents the main components of the HLDS. 


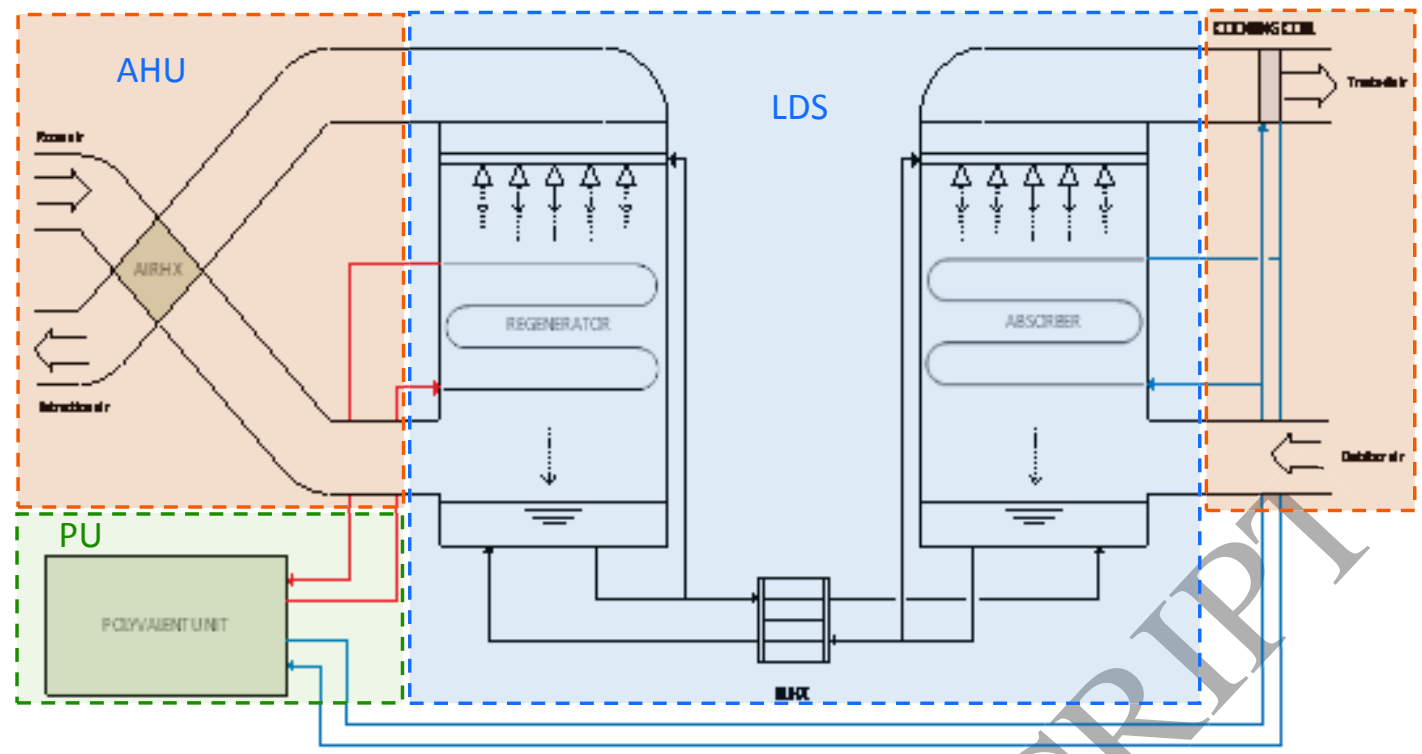

Figure 2. Diagram representing the main components of an HLDS

Ambient design conditions are $30^{\circ} \mathrm{C}$ and $80 \%$ relative humidity, according to Ashrae [12], and interior design conditions are set to $25^{\circ} \mathrm{C}$ and $60 \%$ relative humidity. In order to satisfy the ventilation requirements, $2500 \mathrm{~m}^{3} / \mathrm{h}$ of air need to be supplied, leading to a latent load of 30.1 $\mathrm{kW}$ and sensible load of $8.5 \mathrm{~kW}$. At design conditions, impulsion air must reach $19.8{ }^{\circ} \mathrm{C}$ and $0.0069 \mathrm{~kg} / \mathrm{kg}$ of dry air. The capacity of the absorber and regenerator is $38 \mathrm{~kW}$ under design conditions, with a liquid-liquid heat exchanger effectiveness of 0.85 . The air/air plate heat exchanger's effectiveness at design conditions is 0.65 and the cooling coil has a cooling capacity of $9 \mathrm{~kW}$. Table 1 shows a detailed summary of both the external/internal design conditions, the internal and ventilation sensible and latent loads.

For the design, rating and simulation of the system, detailed thermodynamic models of the main components (absorber, regenerator, liquid-liquid heat exchanger) of the HLDS have been carried out.

Table 1. Design conditions and loads.

\begin{tabular}{|l|c|}
\hline Ambient design conditions & $30^{\circ} \mathrm{C} / 0.0215 \mathrm{~kg} / \mathrm{kg}$ dry air \\
\hline Comfort design conditions & $25^{\circ} \mathrm{C} / 0.0119 \mathrm{~kg} / \mathrm{kg}$ dry air \\
\hline Ventilation rate & $2500 \mathrm{~m} / \mathrm{h}$ \\
\hline Internal sensible heat load & $3.5 \mathrm{~kW}$ \\
\hline Ventilation sensible heat load & $5 \mathrm{~kW}$ \\
\hline Total sensible heat load & $8.5 \mathrm{~kW}$ \\
\hline Internal latent heat load & $8.8 \mathrm{~kW}$ \\
\hline Ventilation latent heat load & $21.3 \mathrm{~kW}$ \\
\hline Total latent heat load & $30.1 \mathrm{~kW}$ \\
\hline
\end{tabular}

The absorber and the regenerator are falling film type, internally cooled and heated respectively. They are comprised by a polypropylene tube bundle, a liquid distribution system based on spray nozzles, and a demister inside a fiber glass tower. Tube bundles are formed by individual modules of tubes, which are linked horizontally in groups of three, and then vertically to form several passes; with a total area of $59 \mathrm{~m}^{2}$. Proper wettability of tubes is a key factor for obtaining good performance in the liquid desiccant cycle, for that reason, the 
polypropylene tubes have received a plasma treatment in order to improve their wettability. Figure 3 shows the schematic configuration of the whole absorber/regenerator units, and the physical configuration of the bundles for heat \& mass exchange.

The air flows from bottom to top getting in contact with the descendent lithium chloride solution, which forms a falling film outside the tubes. The rich $\mathrm{LiCl}$ solution absorbs humidity from the air in the absorber, meanwhile the poor $\mathrm{LiCl}$ solution desorbs humidity enriching the solution in the regenerator. Cold $\left(15^{\circ} \mathrm{C}\right)$ and hot water $\left(55^{\circ} \mathrm{C}\right)$ coming from the Polyvalent Unit flow inside the absorber and regenerator tubes, respectively, cooling the solution and the air during the absorption process (exothermic reaction), and heating the solution and the air during the regeneration process (endothermic reaction).

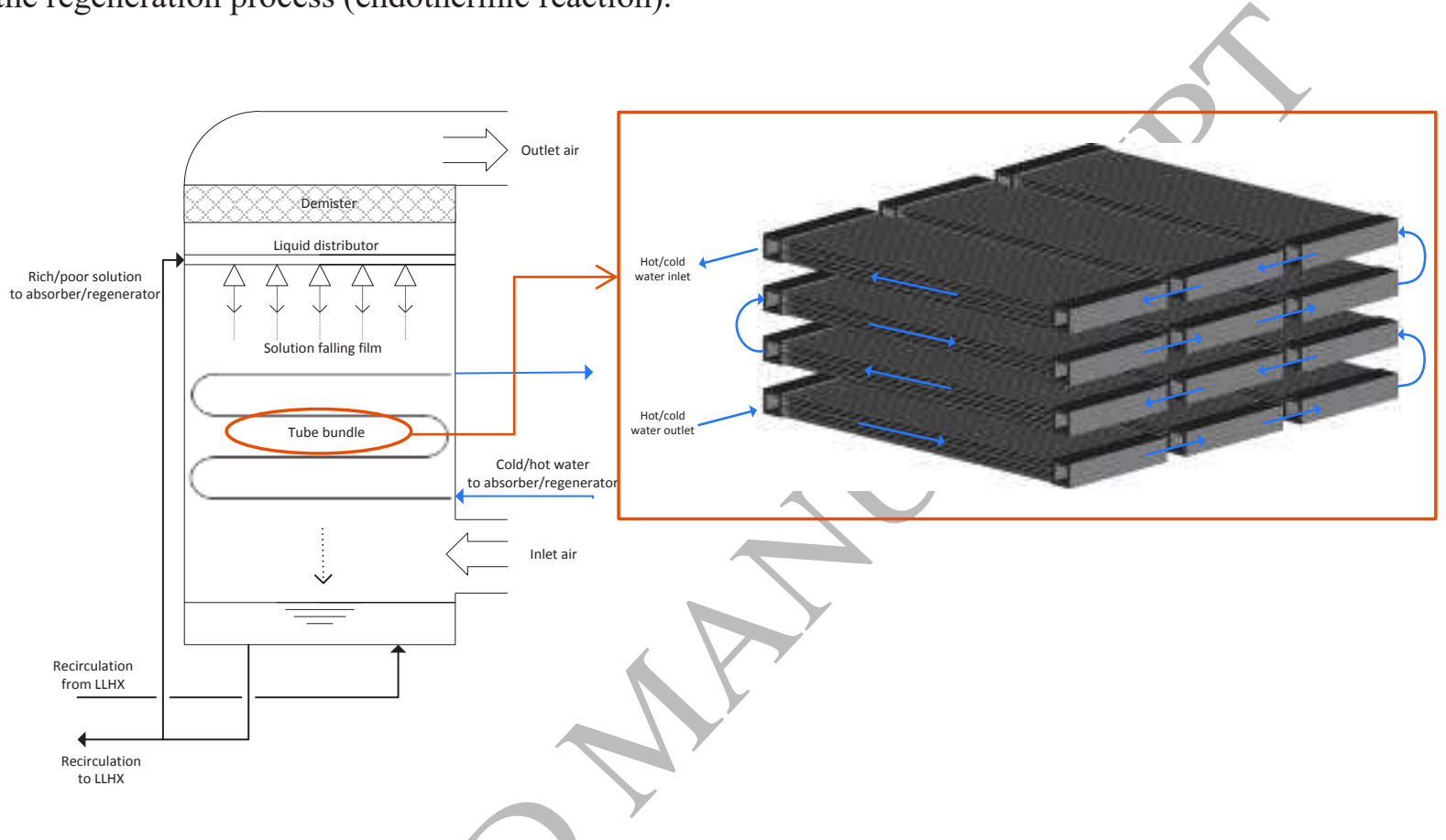

Figure 3. Scheme of the absorber/regenerator units, and the tube bundle layout

Models for the falling film absorber and regenerator are based on the theoretical model described by Gommed and Grossman [13], formulating the heat \& mass balances, and discretizing both air-solution contactors. The reason for the discretization is that neither the air water content nor the enthalpy at the air-solution interface exhibits a linear behavior along the interface; therefore by dividing the single exchanger unit into several sub-exchangers, the error due to the non-linearity was minimized, as explained by Gommed et al. [14]. The number of required sub-units, depends on the dimensionless ratio of mass transfer coefficient times area divided by the air flow rate; in the designed prototype that number yields a total of three subunits.

The developed absorber and regenerator model needs the heat and mass transfer coefficients for the sizing calculation. Since the number of available correlations for the HTC prediction in a falling-film type absorber/regenerator in a liquid desiccant application are scarce; an alternative, which was suggested by Hellmann \& Grossman [15], is to implement a correlation developed for evaporative cooling coils. Therefore, after analyzing different options, the correlation proposed by Bykov et al. [16] was implemented in the detailed thermodynamic model. In addition, for the calculation of the mass transfer coefficient the correlation proposed by Queiroz et al. [17] for an air-drier for a liquid dehumidifier system was used. In order to validate the correlations for the liquid desiccant application, the values experimentally obtained 
by Gommed et al. [14] have been compared with the values obtained from the implemented correlations for the same working conditions in the absorber; the results are presented in Table 2.

Table 2: Calculated/Experimental H\&MTC, Absorber.

\begin{tabular}{|l|c|c|}
\hline Item & Calculated & Experimental \\
\hline $\begin{array}{l}\text { Resulting solution-tube } \\
\text { thermal resistance }\left[\mathrm{m}^{2} \mathrm{~K} / \mathrm{W}\right]\end{array}$ & 0.00154 & 0.00148 \\
\hline $\begin{array}{l}\text { Resulting solution-tube Heat transfer coefficient } \\
{\left[\mathrm{W} / \mathrm{m}^{2} \mathrm{~K}\right]}\end{array}$ & 650 & 675 \\
\hline $\begin{array}{l}\text { Mass transfer coefficient between air-solution } \\
\text { interface and the air stream }\left(\mathrm{kg} / \mathrm{m}^{2} \mathrm{~s}\right) .\end{array}$ & 0.06 & 0.05 \\
\hline
\end{tabular}

The liquid-liquid heat exchanger is used to precool the solution going to the absorber, and to preheat the solution entering the regenerator. For its sizing and rating, a deterministic model based on the $\varepsilon$-NTU method and using the correlations proposed by Martin [18] has been developed.

Thus, the LDS model represents in a realistic way all critical components, absorber, regenerator and LLHX, for different working/design conditions.

In addition, the AHU main components' models were implemented in the whole HLDS's model. The air heat exchanger is a compact plate heat exchanger, with cross-flow configuration, made of aluminum and with internal fins to increase the heat transfer between both air streams. The use of such equipment enables considerable savings (around 40\%) to be achieved in the operating costs of air conditioning plants, and thus the saving of energy that would otherwise be lost. In the HLDS it is used for preheating the air entering the regenerator. It is modelled by using the $\varepsilon$-NTU method.

The cooling coil has been modelled by using the model described in ASHRAE [19]. This model is based on $\varepsilon$-NTU and LMTD and LMHD equations and uses Braun's hypothesis [20] to model the behavior of the cooling coil in an air handling unit (AHU). Normally, cooling coils in AHUs deal with sensible and latent cooling loads, condensing water from air in the surface of the tubes. In this case, although the cooling coil serves for dealing only with sensible cooling loads and no condensation should occur on the tube surface, the model includes also the wet coil approach, in case the cooling coil may be used for dehumidification as well.

The polyvalent unit is a heat pump (NRP 200 model from Aermec [21]) which is able to provide heating and cooling simultaneously; by recovering the heat of condensation in a water circuit through the condenser when the machine is working on dual mode, and dissipating condensation heat to the air when the machine is working on cooling mode. Therefore, it is used in cooling mode when the LDS is only dehumidifying and cooling (regenerator off), or in dual mode when the system is regenerating $\mathrm{LiCl}$ solution as well, with no need from another external source of heat.

Figure 4 shows the Piping \& Instrumentation Diagram of the Hybrid Liquid Desiccant System. The air streams are represented in blue, the solution streams in green and the water streams in purple (cold water stream) and orange (hot water stream).

The system has been designed to ensure an independent control of temperature and humidity levels. Absorber operation is controlled in order to achieve the required dehumidification level (humidity set point), while the cooling of air to the required set point temperature is achieved by controlling the cooling coil in the AHU. The regenerator is controlled in order to maintain the 
solution concentration between certain levels, which guarantee absorber's dehumidification capacity. The system achieves the temperature set point in each zone by maintaining constant supply temperature, and variable air flow rate in each zone as a function of the return temperature, making use of dampers in each zone. The humidity level is controlled in the return stream. The polyvalent unit has its own internal control in order to supply the chilled water and the hot water at fixed set point temperatures.

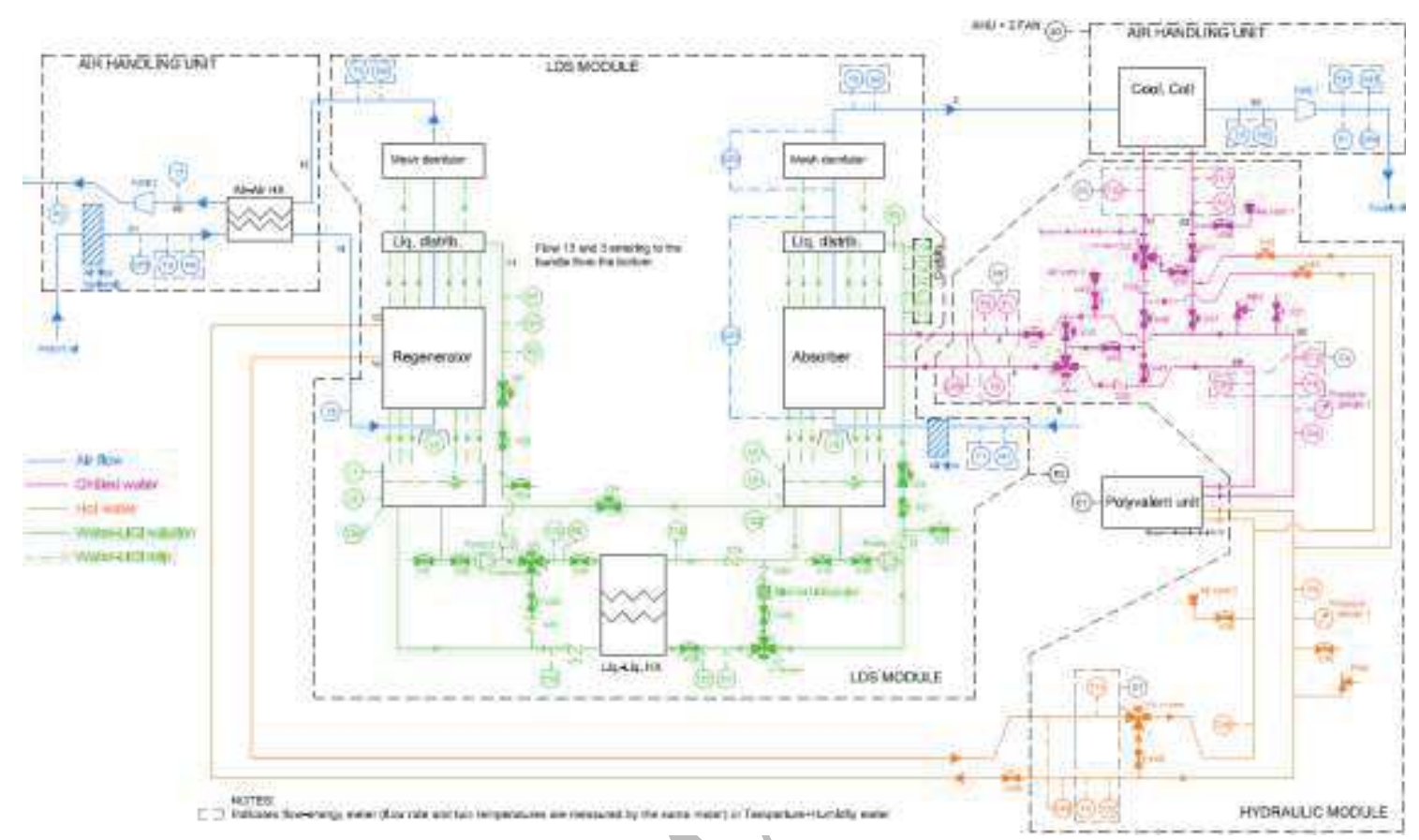

Figure 4. Piping \& Instrumentation Diagram of the Hybrid Liquid Desiccant System.

\section{Data reduction}

As shown in the Piping and Instrumentation Diagram (Figure 4), temperatures, pressures and flow rates have been measured in each of the subsystems (air streams in the AHU, water streams in the Hydraulic Circuit, and LiBr streams in the solution circuit).

For the purpose of the Energy efficiency ratio calculation carried out in this work, the measured parameters include the following.

- Absorber inlet temperature and relative humidity $\mathrm{T}_{1}\left({ }^{\circ} \mathrm{C}\right), \mathrm{H}_{1}(\%)$; which correspond to ambient conditions.

- Cooling coil outlet temperature and relative humidity, $\mathrm{T}_{3}\left({ }^{\circ} \mathrm{C}\right), \mathrm{H}_{3}(\%)$.

- Differential pressure at the outlet of the system, $\mathrm{DP}_{4}(\mathrm{~Pa})$, in order to calculate the air flow rate into the system.

- Polyvalent unit energy power, $\mathrm{PU}_{\text {ActiveEnergy }}(\mathrm{kW})$.

The rest of the measured variables have been used for energy and mass balance calculations, and calculation of the heat and mass transfer coefficients, which are beyond the scope of this paper. Table 3 shows the specifications of the measuring devices.

Table 3. Specifications of the measuring devices.

\begin{tabular}{|l|l|l|l|}
\hline Measured parameters & Sensor & Accuracy & Measuring range \\
\hline $\mathrm{T}_{1}, \mathrm{~T}_{3}$ & Regin HTDT2500 & $0.3 \mathrm{~K}$ at $20^{\circ} \mathrm{C}$ & $0-50^{\circ} \mathrm{C}$ \\
\hline $\mathrm{H}_{1}, \mathrm{H}_{1}$ & Regin HTDT2500 & $2.5 \%$ at $20^{\circ} \mathrm{C}$ & $10-95 \%$ \\
\hline $\mathrm{DP}_{4}$ & Regin DTL310 & $1 \%$ at full scale & $0-1000 \mathrm{~Pa}$ \\
\hline
\end{tabular}


Based on the measured temperature and relative humidity of the inlet air (supply air at ambient conditions) and outlet streams (outlet air from the cooling coil) to the system, the water vapor saturation pressure $\left(\mathrm{P}_{\text {sat }}\right)$ and the absolute humidity $(\mathrm{W})$ values of each stream are derived from the following equations [22]:

$$
\begin{aligned}
& P_{\text {sat }}(\mathrm{Pa})=611.6441 \cdot 10^{\left(\frac{7.591386 \cdot T}{T+240.7263}\right)} \\
& W\left(\frac{\mathrm{kg}}{\mathrm{kg} g_{\text {dry air }}}\right)=\frac{0.62 \cdot H \cdot \frac{P_{\text {sat }}}{100}}{100000-\left(\frac{H \cdot P_{\text {sat }}}{100}\right)}
\end{aligned}
$$

With the calculated absolute humidity the enthalpy (h) and density $(\rho)$ of the air for both entrance and exhaust conditions is calculated based on the following equations:

$$
\begin{aligned}
& h(\mathrm{~kJ} / \mathrm{kg})=1.006 \cdot T+W \cdot(1.84 \cdot T+2501) \\
& \rho=\frac{1+W}{1+1.609 \cdot W} \cdot \frac{100000}{(T+273.15) \cdot 286.9}
\end{aligned}
$$

Mass flow rate of the air stream $\left(\mathrm{M}_{\text {sup }}\right)$ is calculated according to the UNE-EN ISO 51671:2003 [23], being $\mathrm{k}$ a factor corresponding to the specific fan used in the AHU:

$$
M_{\text {sup }}=\frac{k \cdot \sqrt{D P_{4}}}{3600} \cdot \rho
$$

The total load $\left(Q_{\text {total }}\right)$ of the HLDS includes the absorber and the cooling coil loads, this accounts for the latent (dehumidification) and sensible (cooling) loads.

$$
Q_{\text {total }}=M_{\text {sup }} \cdot\left(h_{1}-h_{3}\right)
$$

Finally, the total dehumidification/cooling capacity of the HLDS $\left(\mathrm{Q}_{\text {total, }}\right)$ and the Total EER (Total_EER $_{\mathrm{h}}$ values in each of the time steps are derived from:

$$
Q_{t o t a l, h}=\frac{1}{n} \sum_{i=1}^{n} Q_{t o t a l, i}
$$




$$
\text { Total_EER }_{h}=\frac{Q_{\text {total }, h}}{P U_{\text {ActiveEnergy }}-P U_{\text {ActiveEnergy }} \text { t0-60min }}
$$

Total_EER $\mathrm{h}_{\mathrm{h}}$ refers to the Energy Efficiency ratio in a certain amount of time, taking into account the total cooling/dehumidification load provided by the system $\left(\mathrm{Q}_{\text {total, } \mathrm{h}}\right)$ in that period of time, and the Energy consumption of the Polyvalent Unit in the same period of time.

An average value of the EER per day has been obtained based on the Total EER values obtained during the period of the day in which the HLDS is operative. The evolution of the daily averaged EER value, is deeply analyzed in the Results and discussion section.

\section{Results and discussion}

The HLDS was installed in Taiwan at the end of October 2015, and after its corresponding commissioning period, has been properly working since November 2015 . The system has been monitored during its operating period under Taiwan climatic conditions, registering all its operation parameters. The independent control of temperature and humidity is successfully achieved, for many different ambient conditions faced by the system. In days where the system is working at full load, meaning that ambient conditions are near to the design ones, the comfort conditions are achieved in the conditioned space, maintaining the room temperature and humidity within the control limits.

Concretely, Error! Reference source not found.Error! Reference source not found.Error! Reference source not found.the evolution of both temperature and humidity during a full load day is shown in Figure 5. Although peak values of temperature and humidity appeared in the first part of the day (from 10h to 16h), which are slightly higher than the design ones, the system is able to maintain both return temperature and humidity values close to the set point. At these conditions, the achieved daily average EER was 3.1. As shown in Figure 6Error! Reference source not found., the internal loads and the ventilation loads requirements are similar to the design ones. The ventilation loads are two to three times higher than the internal loads.
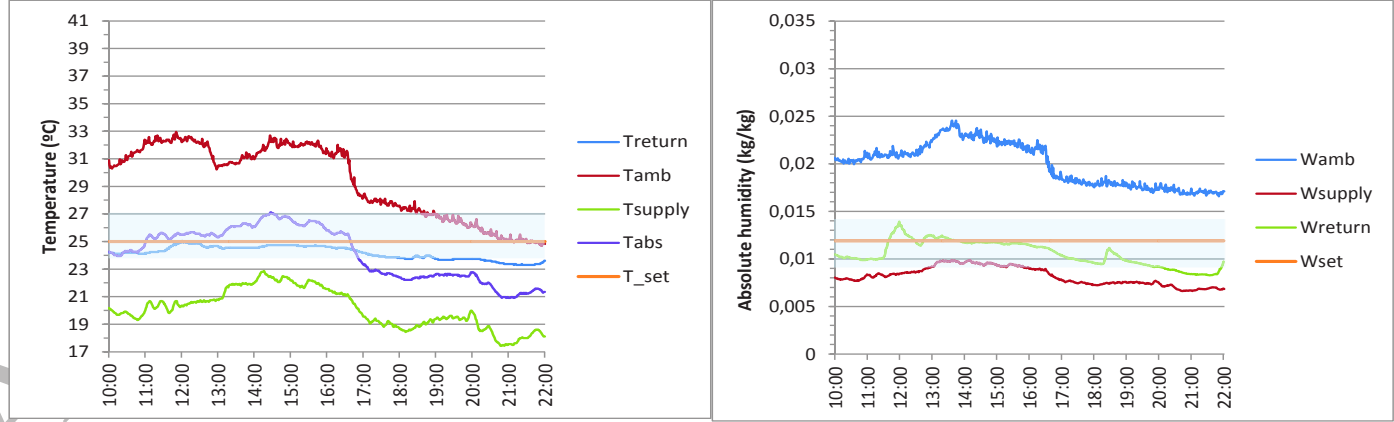

Figure 5. Evolution of temperature and humidity during a full load day, 26/04/2017. 


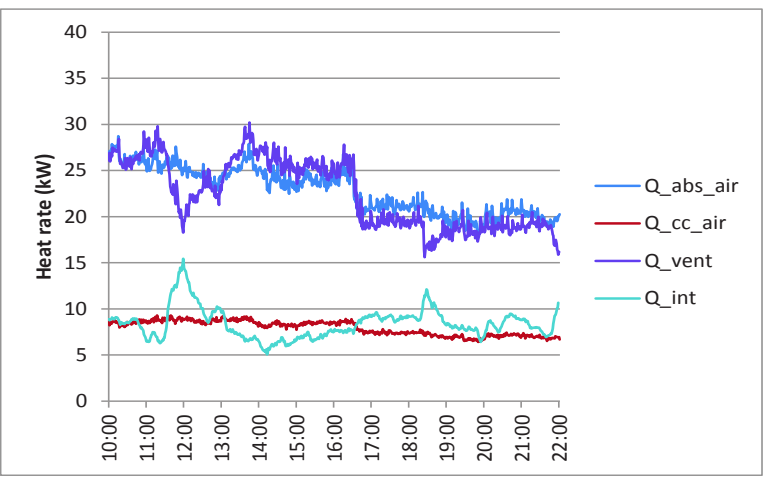

Figure 6. Evolution of thermal loads during a full load day, 26/04/2017.

Furthermore, another day in which the ambient temperature is around the design value (30 $\left.{ }^{\circ} \mathrm{C}\right)$, and the ambient humidity is slightly above the design value $(0.0215 \mathrm{~kg} / \mathrm{kg}$ dry air $)$ is represented in Figure 7. As can be seen, the return temperature achieves the defined set point correctly. On the other hand, although humidity is usually maintained inside the defined hysteresis (blue band), it presents some peak values mainly due to the ventilation and internal loads in the locker rooms. (see Figure 7). Nevertheless, the design comfort conditions were accomplished almost all day, reaching to a daily average EER value of 3.7.

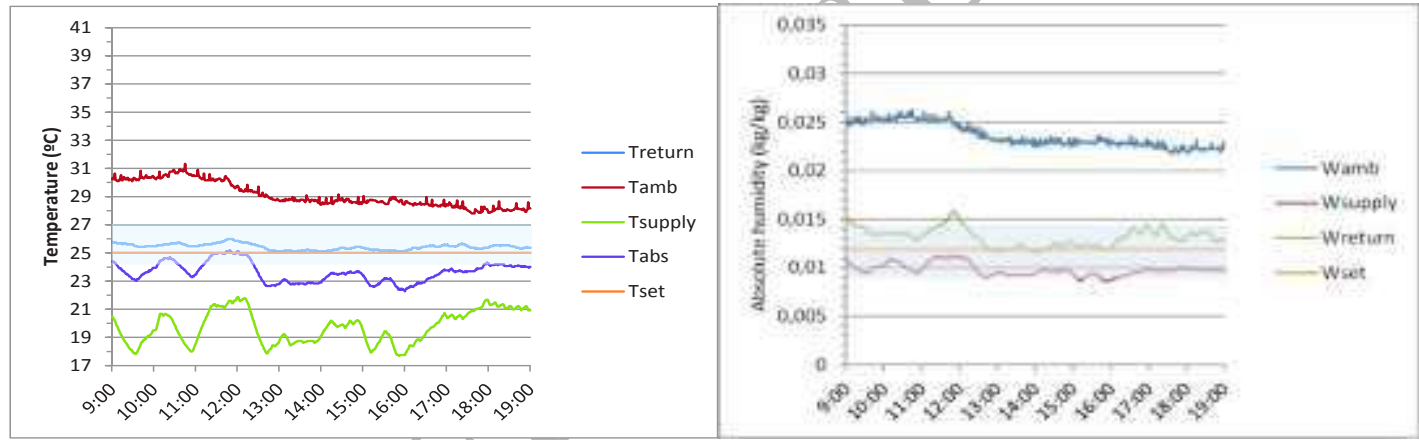

Figure 7. Evolution of temperature and humidity during a full load day, 17/06/2017.

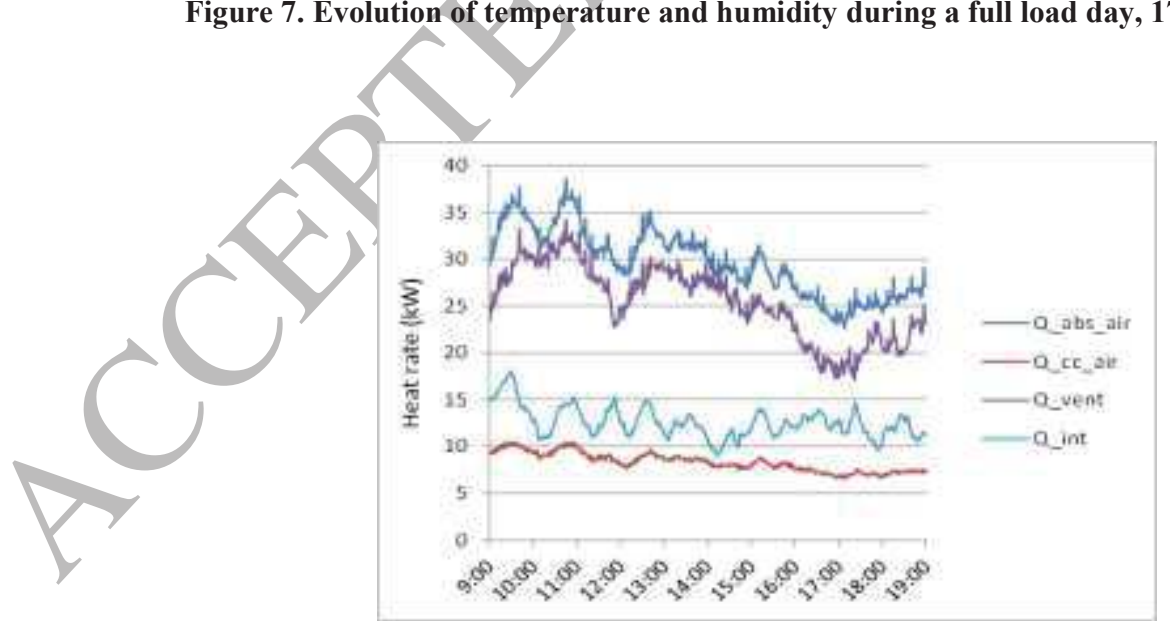

Figure 8. Evolution of thermal loads during a full load day, 17/06/2017

In addition, some days with the system working at overload conditions (higher temperature and humidity levels than the design values) are analyzed. In these kinds of days, the highest EER values are achieved. In Figure 9 the evolution of temperature and humidity during the day with the highest EER achieved (around 4.6) is presented. 

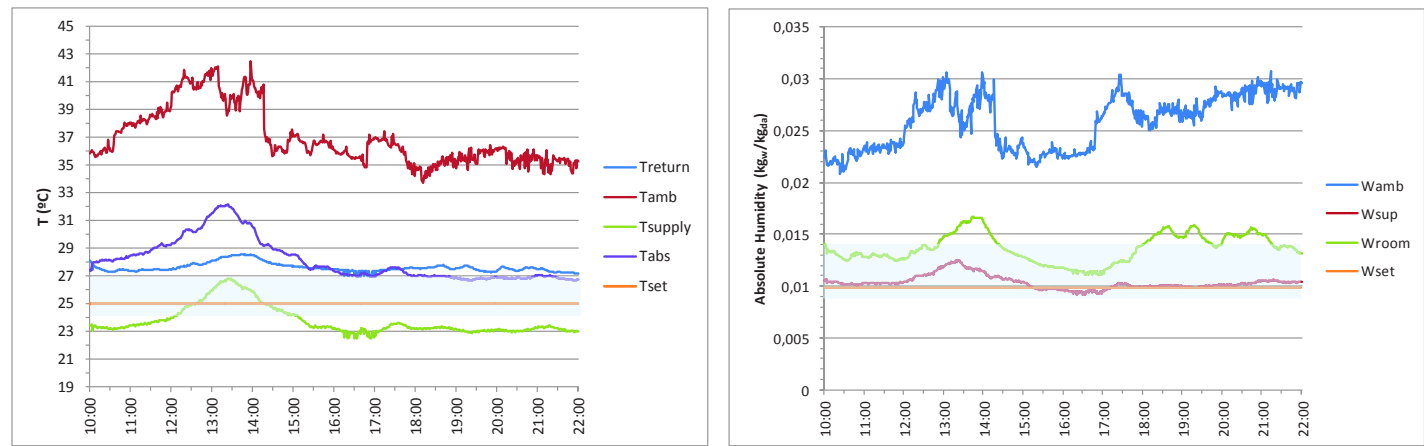

Figure 9. Evolution of temperature and humidity during an overload day, 19/07/2016.

As can be seen in Figure 9, the system tries to maintain the temperature and humidity values inside the system hysteresis (blue band), i.e., in between the maximum and minimum values of temperature and humidity fixed by the system control parameters. Anyway, the system is working far away from the design conditions, the ambient conditions in Taiwan during the analyzed period are higher than $34^{\circ} \mathrm{C}$ and $0.025 \mathrm{~kg} / \mathrm{kg}_{\text {dryair }}$ during the whole day, achieving peak values of up to $42^{\circ} \mathrm{C}$ and $0.030 \mathrm{~kg} / \mathrm{kg}_{\text {dryair }}$.

On the other hand, it should be mentioned that the internal loads are maintained around the design values. Nevertheless, the ventilation loads logically are much higher than the design values, as can be seen in Figure 10.

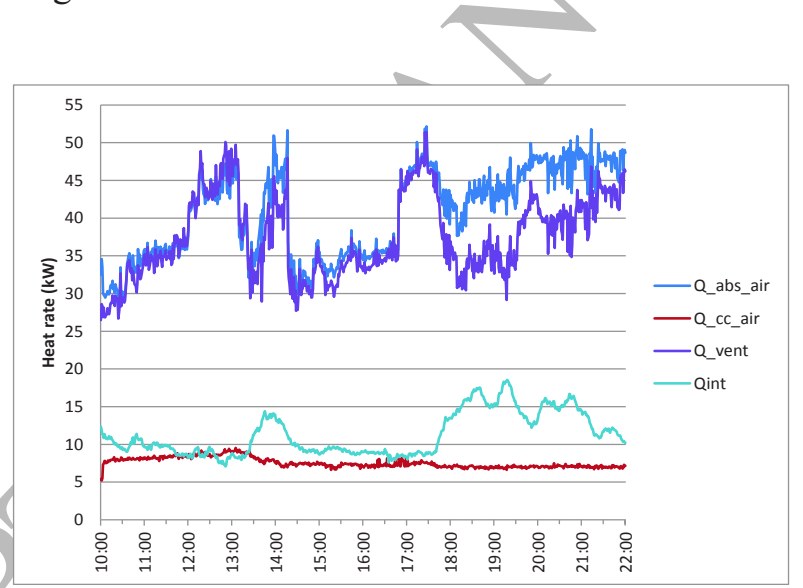

Figure 10. Evolution of thermal loads during an overload day, 19/07/2016.

In order to analyze in detail the behavior of the system working in overload conditions, another representative day has been selected and analyzed. During this day the value of the EER achieved by the system is around 4.1. Checking Figure 11, in which the evolution of temperature and humidity during the system working period is presented, it can be seen that the return temperature is maintained inside the blue band, despite facing ambient temperature values of $36^{\circ} \mathrm{C}$ in the first part of the day. Moreover, the humidity peak values sometimes exceed the blue band. This is mainly because of the combination of two factors, first of all, the ambient humidity values are $5 \mathrm{~g} / \mathrm{kg}_{\text {dry air }}$ higher than the design ones, secondly the maximum values related to internal loads achieved are around $15 \mathrm{~kW}$. 

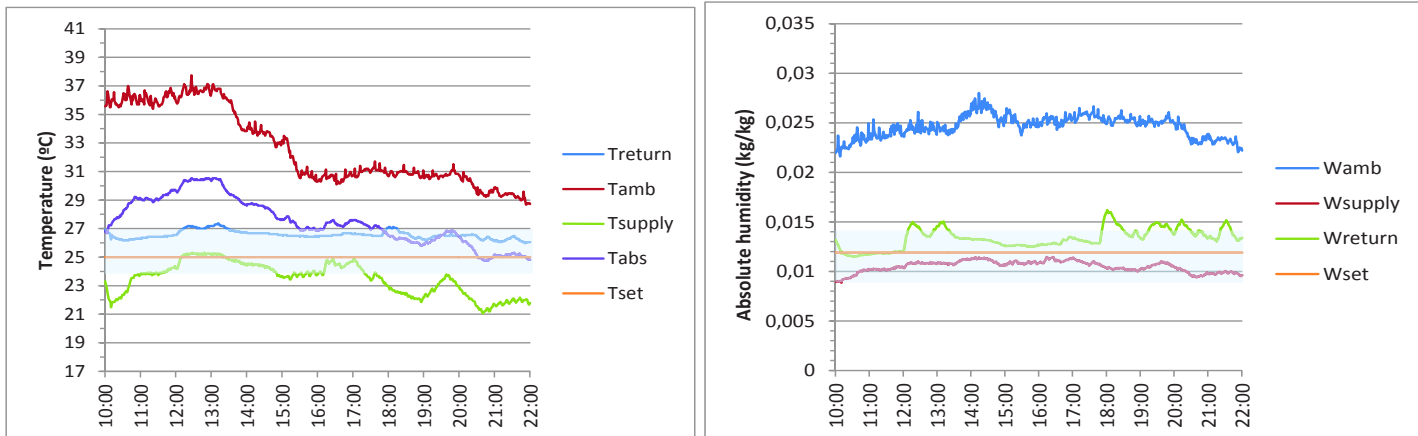

Figure 11. Evolution of temperature and humidity during an overload day, 21/06/2016.

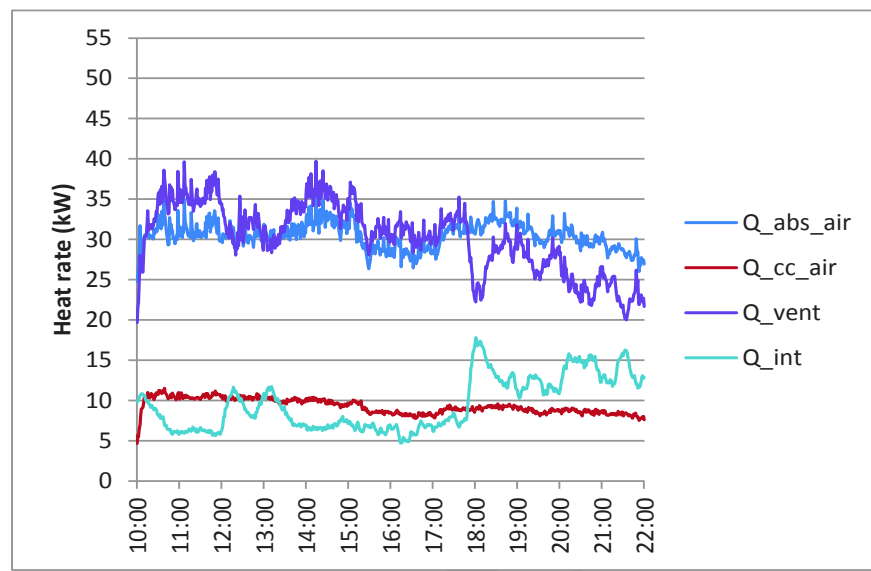

Figure 12. Evolution of thermal loads during an overload day, 21/06/2016.

After analyzing the behavior of the system during the previously presented representative days, a direct relationship between the EER of the system and total loads has been identified. Therefore, an analysis of the evolution of the EER of the system operating at partial loads, design conditions and over-design conditions has been carried out, i.e., EER vs Partial load ratio (PLR). The value of the PLR represents the ratio between the actual load of the system at each period of time and the load of the system in the design conditions.

In order to assure that the analyzed tendency would be independent from the gradual aging of the units, mainly due to the wettability on plasma treated tubes, a comparison of the daily average EER depending on the Partial load ratio (PLR) during two years of operation (2016 and 2017), is presented. 


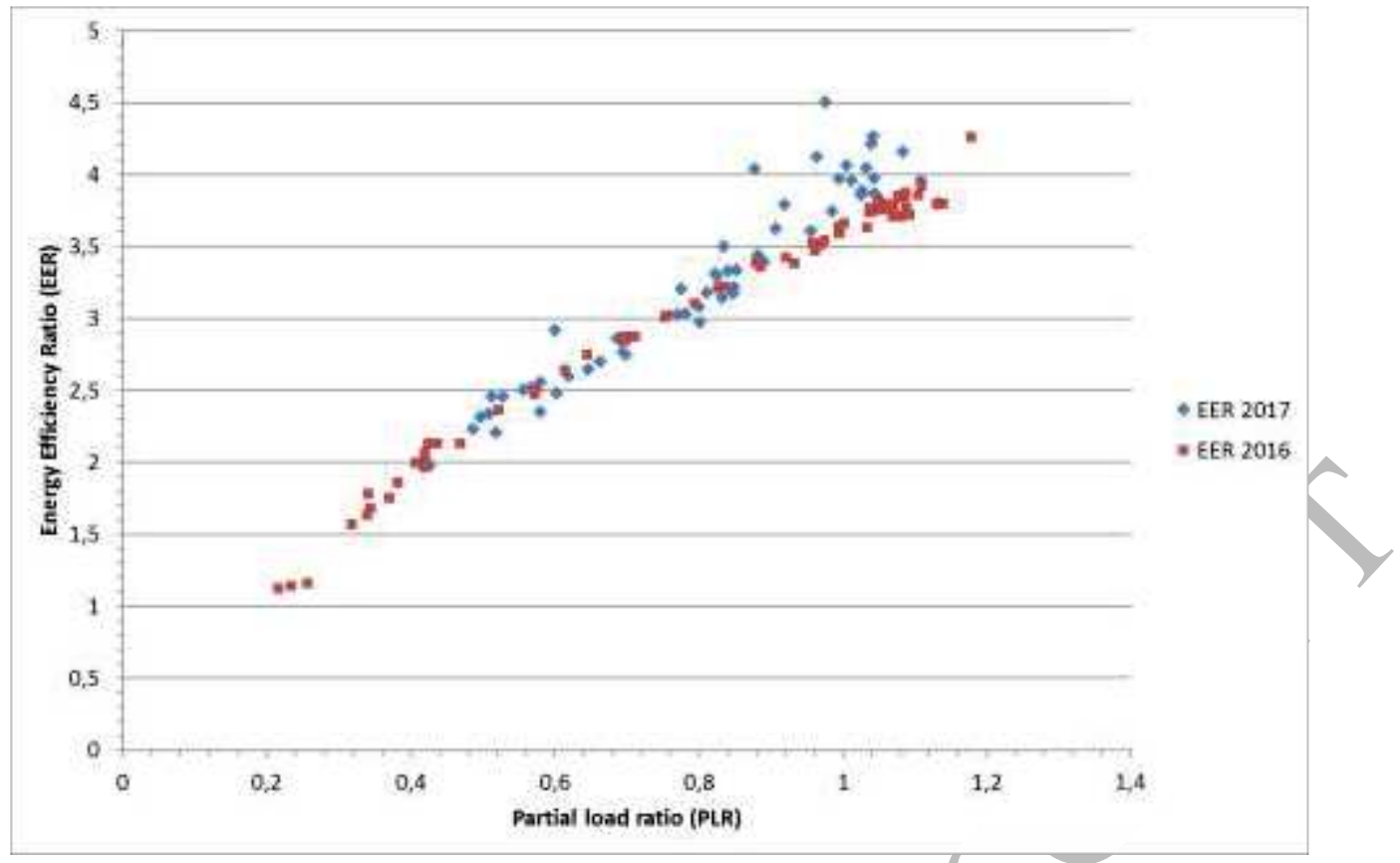

Figure 13. Evolution of the Energy efficiency ratio vs total loads.

As can be seen in Figure 13, the behavior is quite similar regardless of the year; the higher the total loads, the better the performance of the HLDS. Understandably, there is a clear dependency between the EER of the HLDS and the efficiency of the compression unit, therefore if the efficiency of the compression unit is improved, the efficiency of the HLDS will be improved in the same ratio.

In addition, a tool developed in the frame of the EU project has been employed in order to develop a comparison between the HLDS and a conventional system operation, for achieving the same comfort conditions during a whole year, based on real climatic data and ventilation internal loads obtained from the demo measurements. The tool was fed by the measured demo site electrical consumption data, hour per hour, day per day. On the other hand, the calculation of the energy consumption for the conventional system was based on the consumption of a chiller for the air-drying process plus the consumption of a heat pump for the required postheating. The energy consumption was then converted to electricity consumption assuming average reference levels and behavior for EER and COP, according to IDAE [24]. The measured electricity consumption of the HLDS during a year is $47.91 \mathrm{MWh}$; and the calculated electricity consumption of a conventional system based on the previously defined realistic assumptions under the same operation conditions leads to $71.54 \mathrm{MWh}$ per year, which leads to $33 \%$ electrical energy savings.

\section{Conclusions}

Thermal design of an HLDS prototype has been carried out based on a deterministic model of each of the main system components. The mechanical design and manufacturing of an HLDS prototype for HVAC applications has been carried out. The prototype was successfully installed and commissioned, and the system is working since November 2015 on a demo site in subtropical climatic zone, having a low sensible heat ratio (SHR) and high ventilation requirements. 
The HLDS has successfully achieved comfort parameters when working in design conditions and an independent control of temperature and humidity is accomplished. The EER reaches values up to 4.6. Moreover, a direct relationship between the EER of the system and PLR has been identified. In this sense, the higher the total loads the better the performance of the HLDS.

The measured energy consumption of the system compared with the theoretical energy consumption of a conventional system under the same operation conditions, leads to around $30 \%$ electrical energy savings.

In resume, the HLDS has beeen proved as an efficient alternative to conventional HVAC systems for high latent load applications with high ambient humidity levels in tropical and subtropical climates.

\section{Acknowledgement}

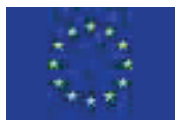

The authors would like to thank the support of the project "nanoCOOL" funded by the Seventh Framework Programme FP7/2007-2013, Project No. 314701.

\section{References}

[1] Giampieri, A., Zhiwei Ma, Smallbone, A., Roskilly, A. P., Thermodynamics and economics of liquid desiccants for heating, ventilation and air-conditioning - An overview. Applied Enery 220 (2018) 455-479.

[2] Coca-Ortegón, A., Prieto, J., Coronas, A. Modelling and dynamic simulation of a hybrid liquid desiccant system regenerated with solar energy. Applied Thermal Engineering 97 (2016) 109-117.

[3] Sanaye, S., Taheri, M., Modeling and multi-objective optimization of a modified hybrid liquid desiccant heat pump (LD-HP) system for hot and humid regions. Applied Thermal Engineering 129 (2018) 212-229.

[4] Abdulrahman Th. Mohammad, Sohif Bin Mat, M.Y. Sulaiman, K. Sopian, Abduljalil A. Alabidi. Survey of hybrid liquid desiccant air conditioning systems. Renewable and Sustainable Energy Reviews Vol 20 (2013) 186-200.

[5] Seiichi Yamaguchi, Jongsoo Jeong, Kiyoshi Saito, Hikoo Miyauchi, Masatoshi Harada, Hybrid liquid desiecant air-conditioning system: Experiments and simulations. Applied Thermal Engineering 31 (2011) 3741-3747.

[6] Mucke, L., Fleig, D., Vajen, K., Jordan, U., Hybrid liquid desiccant air-conditioning systems: A conceptual study with respect to energy saving potentials. International Journal of refrigeration 69 (2016) 64-73.

[7] B. Shaji Mohan, Shaligram Tiwari, M.P. Maiya. Experimental investigations on performance of liquid desiccant-vapor compression hybrid air conditioner. Applied Thermal Engineering 77 (2015), 153-162.

[8] Abdulrahman Th. Mohammad, Sohif Bin Mat, M.Y. Sulaiman, K. Sopian, Abduljalil A. Alabidi, Survey of liquid desiccant dehumidification system based on integrated vapor compression technology for building applications. Energy and Buildings, Vol 62 (2013) 1-14.

[9] World HVAC Equipment Industry Study with Forecasts for 2016 \& 2021 
[10] Fina, A., Guerriero, A., Colonna, S., Carosio, F., Saracco, G., Polymer-based materials for the application in Liquid Desiccant heat exchangers. V Congreso Iberoamericano de Ciencias y Técnicas del frío. (Tarragona, June 18-20, 2014).

[11] Prieto, J., Ortiga, J., Coronas, A., Experimental performance of polymeric air-solution contactors for liquid desiccant systems. Applied Thermal Engineering 121 (2017) 576-584.

[12] Ashrae Handbook: Fundamentals (2009). Chapter 14. Climatic Design Information.

[13] K. Gommed, G. Grossman. Improved Simulation Model for Air-Liquid Contactors in Open Absorption Air Conditioning Systems. Proceedings, the International Sorption Heat Pump Conference, College Park, MD, USA, March 31-April 3 (2014).

[14] Gommed, K., Grossman, G., Prieto, J., Ortiga, J., Coronas, A., Experimental Comparison between Internally and Externally Cooled Air-Solution Contactors, International Sorption Heat Pump Conference, Doc. 1095, Washington, March 31-April 3, (2014).

[15] Hellmann, H.-M., Grossman, G., Simulation and analysis of an open-cycle dehumidifierevaporator-regenerator (DER) absorption chiller for low-grade heat atilization, Int. J. Refrig. Vol. 18, No. 3, pp 177 189, (1995).

[16] Bykov, A.V., V.A. Gogolin and N.V. Tovaras, Investigation of heat, mass transfer and fluid flow characteristics in evaporative condensers, International Journal of Refrigeration, Vol. 7, pp. 342-347, 1984.

[17] Queiroz, A.G., Orlando, A.F., Saboya, F.E.M.Performance analysis of an air-Drier for a Liquid Dehumidifier Solar Air Conditioning System, Journal of Solar Energy Engineering, 1988, Vol. 110, pp. 120-124.

[18] Martin, H., Pressure Drop and Heat Transfer in Plate Heat Exchangers. VDI Heat Atlas, 2010, pp. 1515-1521.

[19] Air-Cooling and dehumidifying coils ASHRAE 2008 HVAC Systems and Equipment Handbook. Chapter 22.

[20] Braun, J.E., Klein, S.A., Mitchell, P.E., Effectiveness models for cooling towers and cooling coils ASHRAE Transactions Vol.92 part 2 (1989), p.164-174.

[21] https://global.aermec.com/en/products/product-sheet/?t=Multipurpose units \&c=CAT_60HZ\&f $=$ chiller_polivalent\&Code $=\mathrm{NRP} \_60 \mathrm{HZ}$ _PO

[22] Ashrae Fundamentals (2013). Chapter 1. Psychrometrics.

[23] Measurement of fluid flow by means of pressure differential devices inserted in circular cross-section conduits running full - Part 1: General principles and requirements (ISO 51671:2003)

[24] IDAE, "CALENER-GT Manual de curvas", 2009. 